\title{
Design Optimization of Composite Submarine Pressure Hull
}

Ranjith $\mathrm{M}^{1}$

${ }^{1}$ PG Scholar, Department of Mechanical Engineering, Alagappa Chettiar Government College of Engineering and Technology,Karaikudi.

\begin{abstract}
The design of composite submarine pressure hull is optimize the Stress and Failure index into consideration using ANSYS Software and Tsai-Wu Failure theory. The FEA value is compared with theoretical results. The composite of EPOXY resin and E-GLASS fiber is used to optimize the failure criteria by using ANSYS software. The failure index 0 the isentropic and orthotropic material should be less than 1 as per the Tsai-Wu criteria. The pressure hull is used to many structural applications such that Pressure Vessels, Aircrafts and Nuclear Submarines. The Failure index value is vary from applied load.
\end{abstract}

Keywords:- Composite cylinders; Optimization; Failure Index; Epoxy; E-Glass.

\section{INTRODUCTION}

Variety of composite structural mode is increased. It is used to Aerospace applications. [1]The composite submarine pressure hull is designed. It is used to withstand the hydrostatic load and pressure. [2] The main development of composite submarine designs will be reach the higher depth of underwater .It have a two hulls, there are inner hull and outer hull. Inner hull is used to maintain the integrity. Outer hull is used to withstand the hydrostatic pressure. [3] The hull is depends upon the external water pressure when the vehicle goes in deep underwater. Composites are used to construction of underwater vehicle due to more weight, strength, stiffness and more corrosion resistance. [4]The main structure of submarines consists of two hulls, one is inner hull and another one is outer hull Inner hull is used to withstand the hydrostatic pressure and the outer hull is used to control the hydrodynamic loads. [5] Underwater vehicles subjected to external pressure are typically cylindrical and spherical. Buckling can occur for such structures, and the load capacity would be dramatically reduced. There has been considerable amount of work carried out on buckling analysis of composites structures. Predicted the minimum buckling pressure of composite shell by two different approached. [6]In this study, analyse the composite submarine pressure hull under external pressure. The work is validation from theoretical value and FEA value. It is used to minimize the induced stress on material under load condition.

\author{
Dr. J. Selwin Rajadurai ${ }^{2}$ \\ ${ }^{2}$ Associate Professor, Department of Mechanical \\ Engineering,
}

Alagappa Chettiar Government College of Engineering and Technology,Karaikudi.

\section{SUBMARINE PRESSURE HULL}

Submarines are created by using the underwater operations. The main structure of submarines consists of two hulls, one is inner hull and another one is outer hull Inner hull is used to withstand the hydrostatic pressure and the outer hull is used to control the hydrodynamic loads. It is used to underwater research and rescue.

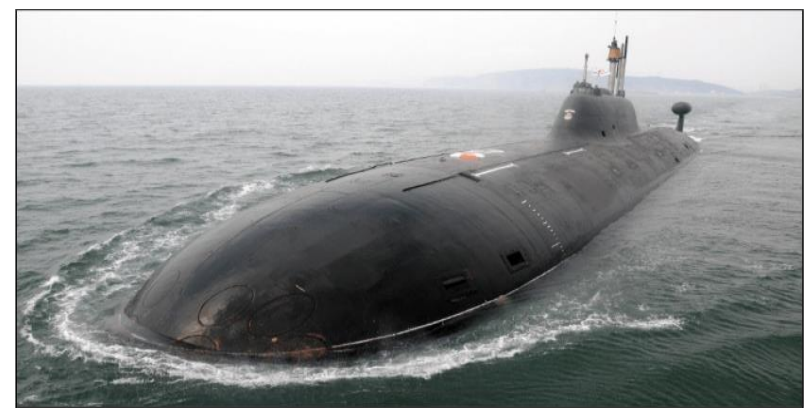

Fig 1:- Submarine Structure (Surfaced Condition).

\section{$>$ Outer Hull and Pressure Hull}

The design of submarines have a single or double hulls, one is inner hull and another one is outer hull Inner hull is used to withstand the hydrostatic pressure and the outer hull is used to control the hydrodynamic loads. It is also known as pressure hull.

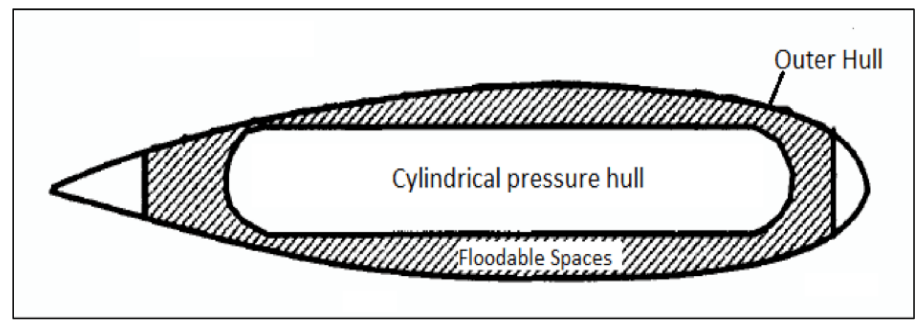

Fig 2:- Pressure hull and Outer hull

\footnotetext{
Material Property

The material of submarines must be withstood the environment and the higher external pressure. Mostly used in materials for design of pressure hull is steels, aluminum, titanium etc.., It is constructed from Epoxy matrix and EGlass fiber because it have a high strength and stiffness.
} 
Material Property for steel

Young's modulus(E) $=2 \mathrm{e} 5 \mathrm{~N} / \mathrm{mm}^{\wedge} 2$

Poisson Ratio $=0.3$

Applied Pressure $=10 \mathrm{~N} / \mathrm{mm}^{\wedge} 2$

Strength Properties of Steel

$\mathrm{S}_{\mathrm{LT}}=S_{L C}=520 \mathrm{~N} / \mathrm{mm}^{2}$

$\mathrm{S}_{\mathrm{Tt}}=S_{T c}=390 \mathrm{~N} / \mathrm{mm}^{2}$

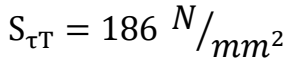

$\mathrm{F}_{1}=0, F_{2}=0, F_{3}=0$

Mechanical Properties of Epoxy/E-glass

$$
\begin{gathered}
E_{x x}=3.4412 \mathrm{GPa} \\
E_{y y}=E_{z z}=6.531 \mathrm{GPa} \\
G_{x y}=G_{z x}=2.433 \mathrm{GPa} \\
G_{y z}=1.698 \mathrm{GPa} \\
\mathrm{v}_{x y}=\mathrm{v}_{z x}=0.217 \\
\mathrm{v}_{y z}=0.336
\end{gathered}
$$

$\rho=1.976 \times 10^{-6} \mathrm{Kg} / \mathrm{mm}^{3}$

Strength Properties of Epoxy/E-glass

$X_{T}=674 \mathrm{MPa}$

$X_{C}=420 \mathrm{MPa}$

$Y_{T}=520 \mathrm{MPa}$

$Y_{C}=406 \mathrm{MPa}$

$S_{L}=282 \mathrm{MPa}$

$S_{T}=306 \mathrm{MPa}$

\section{* TSAI-WU FAILURE THEORY}

This theory is used to orthotropic composite materials only. Tsai-Wu criterion predicts failure when the failure index value is reaches 1 .

$F_{1} \sigma_{11}+F_{2} \sigma_{22}+F_{3} \sigma_{33}+F_{11} \sigma_{11}^{2}+F_{22} \sigma_{22}^{2}+F_{33} \sigma_{33}^{2}+$ $2 F_{12} \sigma_{11} \sigma_{22} \leq 1 \ldots$ (1)

$F_{1}=\frac{1}{s_{L t}}-\frac{1}{s_{L c}} \quad ; F_{2}=\frac{1}{s_{T t}}-\frac{1}{s_{T c}} ; F_{3}=0$

$F_{11}=\frac{1}{S_{L t} S_{L c}} ; \quad F_{22}=\frac{1}{S_{T t} S_{T c}} ; \quad F_{33}=\frac{1}{S_{L T S}^{2}}$

$$
F_{12}=-\frac{1}{2}\left(F_{11} F_{22}\right)^{1 / 2}
$$

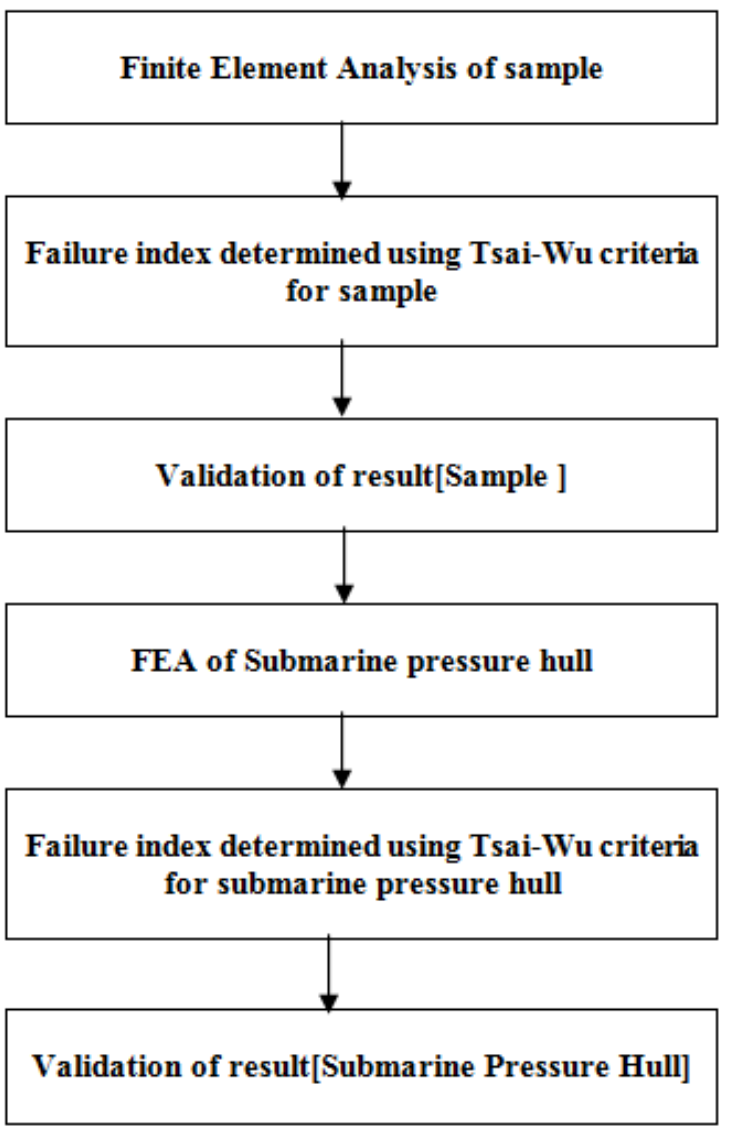

Fig 3

Validation of Finite Element Analysis

ANSYS, commercial software for finite element analysis, was used for the Failure Index analysis. which contained 4-node quadrilateral elements for the cylindrical. The FEA model is as shown in Figure 3. The forces specified on the finite element were the same as those of underwater vehicles loading condition.

\section{Result of Pressure Hull for Isentropic Material for Steel}

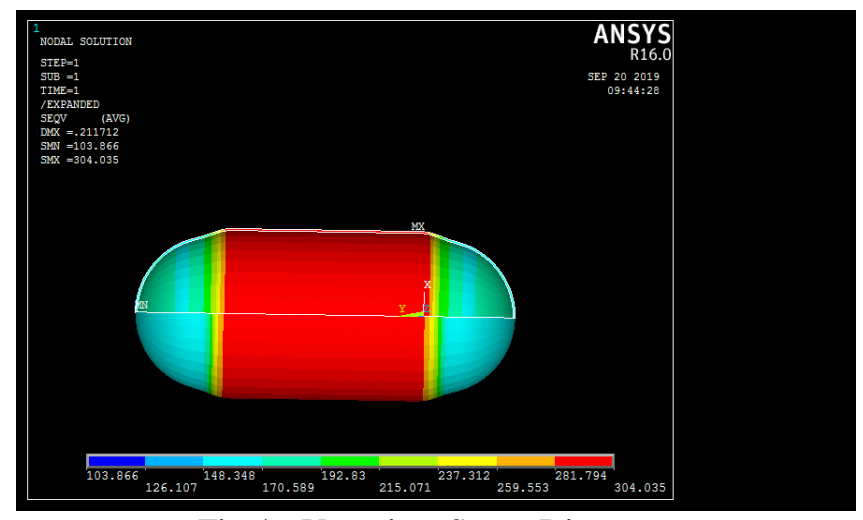

Fig 4:- Vonmises Stress Diagram 
ISSN No:-2456-2165

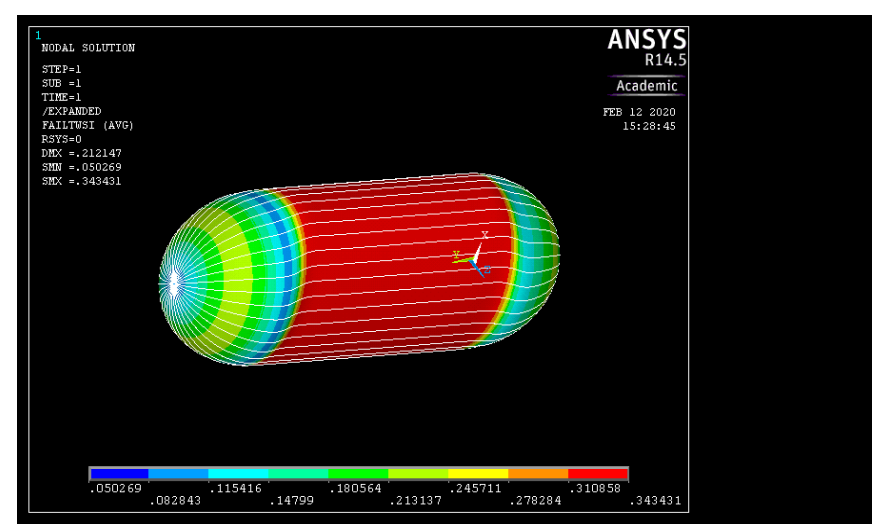

Fig 5:- Failure Index

IV. RESULT ANALYSIS

\begin{tabular}{|c|c|c|}
\hline Results & $\begin{array}{c}\text { Stress Value } \\
\text { In(N/mm }{ }^{2} \text { ) }\end{array}$ & $\begin{array}{c}\text { Failure } \\
\text { Index(Tsai-wu) }\end{array}$ \\
\hline $\begin{array}{c}\text { Finite Element } \\
\text { Analysis Result }\end{array}$ & $\mathbf{3 0 4 . 0 3 5}$ & $\mathbf{0 . 3 4 3 4}$ \\
\hline $\begin{array}{c}\text { Theoretical } \\
\text { Result }\end{array}$ & $\mathbf{3 3 3 . 3 3}$ & $\mathbf{0 . 5 9 6 5}$ \\
\hline
\end{tabular}

Table 1:- Result Analysis for Isentropic Steel Material

Result of Pressure Hull for Orthotropic Material (Epoxy \& E-Glass)

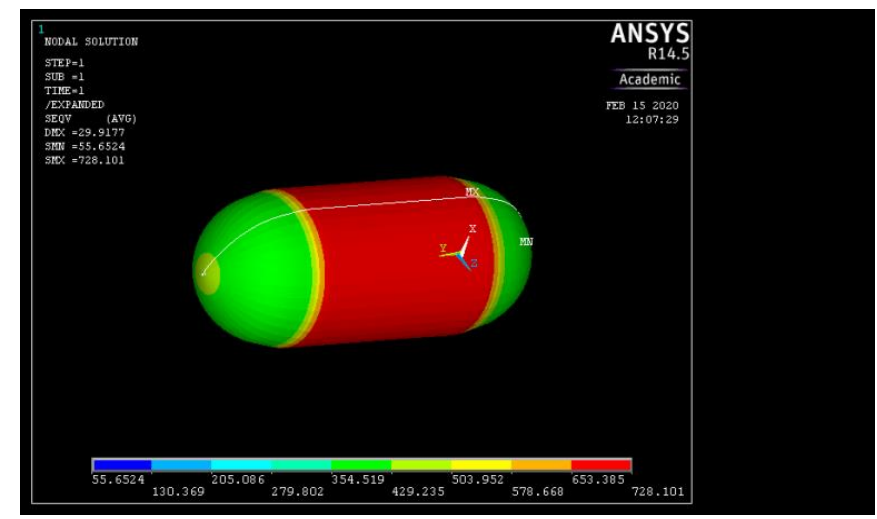

Fig 6:- Von-Mises Stress (Epoxy/E-Glass)

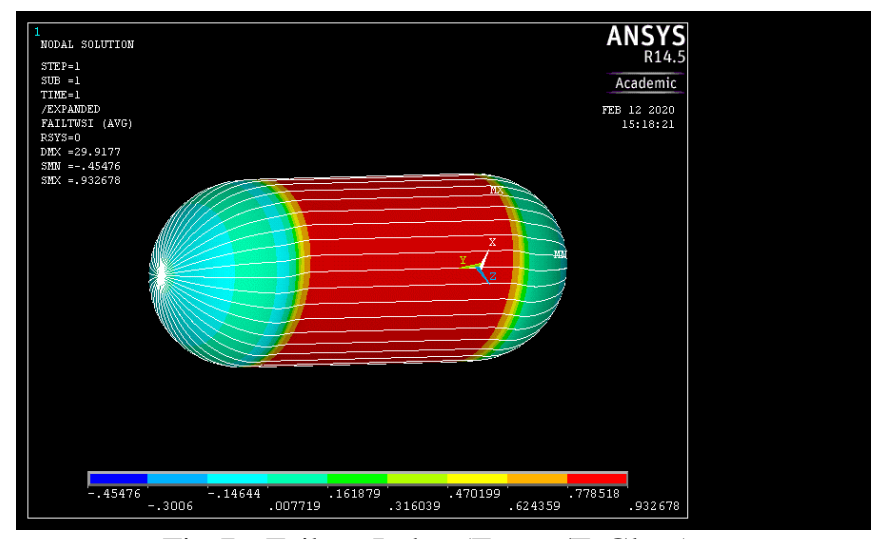

Fig 7:- Failure Index (Epoxy/E-Glass)
The pressure hull was analyzed with the respective properties of the Epoxy resin and E-glass fiber material to obtain the failure index values for various pressure. The table 1 shows the values of failure index and pressure.

\begin{tabular}{|c|c|}
\hline Pressure $\left(\mathrm{N} / \mathrm{mm}^{2}\right)$ & Failure Index \\
\hline 5 & $-0.2623 E^{-01}$ \\
\hline 10 & $-0.2176 E^{-01}$ \\
\hline 15 & 0.1455 \\
\hline 20 & 0.5180 \\
\hline 21 & 0.6119 \\
\hline 22 & 0.7124 \\
\hline 23 & 0.8193 \\
\hline 24 & 0.9327 \\
\hline 25 & 1.0526 \\
\hline
\end{tabular}

Table 2:- Failure Index Values for Various Pressure

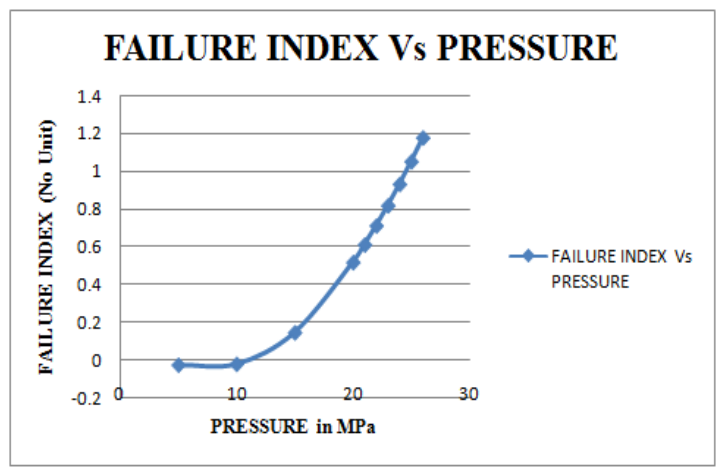

Fig 8:- Failure Index \& Pressure

\begin{tabular}{|c|c|c|}
\hline Results & $\begin{array}{c}\text { Stress Value } \\
\mathbf{I n}\left(\mathbf{N} / \mathbf{m m}^{\mathbf{2}} \text { ) }\right.\end{array}$ & $\begin{array}{c}\text { Failure Index } \\
\text { (Tsai-wu) }\end{array}$ \\
\hline $\begin{array}{c}\text { Finite Element } \\
\text { Analysis Result }\end{array}$ & 728.101 & 0.9327 \\
\hline $\begin{array}{c}\text { Theoretical } \\
\text { Result }\end{array}$ & 800 & 0.8928 \\
\hline
\end{tabular}

Table 3:- Result Analysis for Composite Material (Epoxy\&E-GlassFiber)

\section{CONCLUSION}

In this paper, evaluate the failure index of submarine pressure hull by using Tsai-Wu criteria. This criterion is used to predict the failure index. The failure index value is more than 1 the material will be failure. The failure index value is less than 1 the material will be safe. The above materials should be better results than other materials.

\section{REFERENCES}

[1]. Professor Tonglili and Dr.MahmoudHelal, "Design Optimization of Composite Elliptical DeepSubmersible Pressure Hull for Minimizing the Buoyancy Factor", Hindawi Publishing Corporation Advances in Mechanical Engineering, 2014.

[2]. Pan Guang"Design optimization of composite cylinders for submersible pressure hulls", 4th International Conference on Mechanical Materials and Manufacturing Engineering (MMME 2016). 
[3]. Mr.Jobil Varghese, "Optimization of submarine ring stiffened composite pressure hull using Numerical Methods", IJISET - International Journal of Innovative Science, Engineering \& Technology, Vol. 5 Issue 4, April, 2018.

[4]. Yong-Jie Pang, Yan-xue Cheng, Xiao-meng Zhu, "Collaborative optimization for ring stiffened composite pressure hull of underwater vehicle based on lamination parameters", B. Li et al. International Journal of Naval Architecture and Ocean Engineering, (2017).

[5]. Ahmad FauzanZakki, Dong MyungBae, SulistiyonoSusilo, Eli AkimSipayung and Suharto, "Structure Design And Characteristic Analysis Of Buckling Strength On Swedge Frame Pressure Hull With Finite Element Analysis", ARPN Journal of Engineering and Applied Sciences,February, 2017. 